\section{GESTÃo DE PESSOAS NAS ORGANIZAÇÕES}

Wilson José Alves Pedro*

\section{Introdução}

Toledo (1986, p.8) define Recursos Humanos como a função que norteia "um conjunto de princípios, estratégias e técnicas que visa contribuir para a atração, manutenção, motivação, treinamento e desenvolvimento do patrimônio humano de qualquer grupo organizado. Seja este grupo, ou organização, pequeno ou grande, seja privado ou público, desempenhe ele atividades de trabalho, de lazer, ação política ou religiosa”.

Apesar da abrangência da conceituação, o nosso recorte no presente artigo delimita a função de recursos humanos em seus princípios, estratégias e técnicas vinculadas às organizações produtivas de trabalho. A proposta é refletir sobre o papel da função de Recursos Humanos, a partir de uma breve visão histórica, apresentando a seguir alguns dos seus “saberes e práticas” a partir dos subsistemas que hoje norteiam as principais responsabilidades, preocupações e atividades da área. Apresentam-se ainda alguns dos desafios contemporâneos que têm sido postos no cotidiano de profissionais que trabalham direta ou indiretamente na gestão de pessoas. A tese que tem mobilizado nossas ações enquanto pesquisador e educador, é que todo profissional é um gestor de pessoas, portanto, deve ter o conhecimento e a sensibilidade para lidar com as pessoas nas organizações. Independente da área de formação e atuação profissional, é consenso que em toda atuação direta ou indireta para o desenvolvimento de projetos há o envolvimento na condução de equipes. Todo profissional deve conhecer, portanto, princípios norteadores da administração de recursos humanos.

*Doutor em Psicologia Social (PUC/SP). Professor Universitário nas áreas de Psicologia Social Administração de Recursos Humanos. Coordenador do Curso de Pós-Graduação Lato Sensu em Administração - Gestão de Recursos Humanos da UNIARA. Pesquisador dos Grupos: Multidisciplinar em Gestão das Organizações (UNIARA) e Psicologia Social e Trabalho (UNIARA). Membro do Núcleo de Pesquisa em Identidade “José Roberto Malufe” (PUC/SP) e do Grupo Políticas e Práticas em Saúde (Ufscar).E-mail: wilsonjosealvespedro@ig.com.br.

REVISTA UNIARA, n.17/18, 2005/2006

\section{Breve contextualização}

O desenvolvimento da área de Recursos Humanos revela uma função que se origina e evolui como resposta às condições históricas, passando por profundas transformações correlatas ao mundo do trabalho. Os fatores contextuais de fins do século XIX e meados do século XX são determinantes para a sua dinâmica.

Tonelli et al. (2002, p.63) apontam que o forte desenvolvimento econômico e tecnológico, as experiências e doutrinas humanistas (do início do século XX), o acirramento das relações de trabalho e o reformismo que surge para apaziguálas, bem como a grande evolução das ciências comportamentais são algumas das influências mais importantes para as transformações da área. O desenvolvimento do capitalismo e da industrialização, a organização científica do trabalho, o desenvolvimento da teoria organizacional e as novas configurações organizacionais que se estruturam de diferentes maneiras, demarcam importantes fases históricas do século XX, gerando aspectos cruciais para a sua auto-afirmação.

Neste macro contexto a área de Recursos Humanos emergiu e se firmou. A Administração de Pessoal, com uma preocupação sobre as rotinas orientadas pelo enfoque legalista e disciplinar das relações interpessoais de trabalho, cede lugar às Relações Industriais, resultantes das novas relações de forças com os movimentos sindicais e trabalhistas, conduzindo a área a se preocupar com as condições de trabalhos e fornecer serviços e benefícios sociais aos trabalhadores. A partir da década de sessenta, a área de Administração de Recursos Humanos começa então a substituir as denominações de Administração de Pessoal e Relações Industriais (sabendo que ainda hoje coexistem em muitas organizações) expandindo suas ações e intervenções em sub-sistemas.

Contemporaneamente, outras denominações surgem: Gestão de Talentos, Gestão de Capital Humano, Gestão de Pessoas preocupando-se agora com a orientação dos “modos de lidar com as pessoas nas organizações”.

De modo geral, a função de Administração de Recursos Humanos, tal como a conceituamos, vincula-se ao âmbito de estudos das Ciências Sociais Aplicadas. Um dos principais pilares é a Administração - área do conhecimento que investiga e intervém sobre a dinâmica das organizações e que dinamiza o conjunto dos recursos - humanos, financeiros, materiais e tecnológicos procurando integrá-los, geri-los e otimizar resultados.

A função de RH visa administrar e gerenciar a cooperação das pessoas, propiciando o alcance e a conciliação dos objetivos organizacionais e individuais. Para tanto, fica evidente a necessidade de um conjunto interdisciplinar de conhecimentos para sua melhor compreensão. O profissional da área utiliza conhecimentos da Psicologia, da Sociologia, da Economia, da Engenharia Industrial, da Medicina do Trabalho, do Direito do Trabalho, dentre outros, uma 
vez que desenvolve práticas que devem se pautar em saberes que visam satisfazer as necessidades dos diversos agentes envolvidos nas relações de trabalho: trabalhadores, empresários, acionistas e a comunidade.

A área de Recursos Humanos deve ser concebida como um "caminho" através do qual as pessoas e organizações procuram atingir e conciliar os interesses diversos contidos nas inter-relações pessoas-organizações-sociedade. Não se trata de um sistema autônomo e independente, com finalidade em si mesma, pois está inserido num quadro maior, político, econômico, jurídico, social e ideológico.

O seu reconhecimento foi consolidado, primeiramente enquanto área técnica, com sua atuação reduzida a questões de administração de pessoal, a partir de exercícios de seus subsistemas. Entretanto, o que observamos é sua potencialização enquanto área estratégica da organização. Daí a reflexão priorizada no presente artigo: um desafio para o presente século. A gestão de pessoas deve ocupar-se também da determinação de objetivos, de políticas, de diretrizes e da estruturação das organizações. Sua missão é conduzir as pessoas com produtividade, eficiência e qualidade à realização dos objetivos organizacionais, de modo conciliatório com as aspirações individuais e sociais. Seu desafio maior é integrar a valorização da organização e a humanização das relações de trabalho.

\section{O sistema e os subsistemas “clássicos” da administração de RH}

Toda organização produtiva tem como um de seus principais objetivos a criação e distribuição de algum produto ou serviço. Neste processo, as organizações aglutinam recursos - materiais, financeiros, mercadológicos, administrativos e humanos. As pessoas nas organizações interagem por meio de relações e interações. Cada vez mais, torna-se mais emergente a necessidade de administrar e gerenciar: a comunicação, a motivação, o desempenho, a liderança, o empreendedorismo, o envolvimento e o comprometimento com o trabalho, a identidade, a qualidade de vida, o sentido do trabalho e a saúde do trabalhador.

Mas com que finalidade administrar as pessoas em uma organização? Segundo Chiavenato (1992, p.133), os principais objetivos da área de Administração de Recursos Humanos são:

1. criar, manter e desenvolver um contingente de recursos humanos com habilidade e motivação para realizar os objetivos da organização;

2. criar, manter e desenvolver condições organizacionais de aplicação, desenvolvimento e satisfação plena dos recursos humanos, e alcance dos objetivos individuais;

3. alcançar a eficiência e eficácia através dos recursos humanos disponíveis.
Neste sentido questionamos: como, por que e para quê criar e alcançar tais objetivos? Afirma Chiavenato: “a Administração de Recursos Humanos consiste no planejamento, na organização, no desenvolvimento, na coordenação e no controle de técnicas capazes de promover o desempenho eficiente do pessoal, ao mesmo tempo em que a organização representa o meio que permite às pessoas que com ela colaboram alcançar os objetivos individuais relacionados direta ou indiretamente ao trabalho. A Administração de Recursos Humanos significa conquistar e manter pessoas na organização, trabalhando e dando o máximo de si, com uma atitude positiva e favorável. Representa todas aquelas coisas não só grandiosas que provocam euforia e entusiasmo, como também aquelas coisas muito pequenas e muito numerosas, que frustram ou impacientam, o que alegram e satisfazem, mas que levam as pessoas a desejar permanecer na organização. Há mais coisas em jogo quando se fala em ARH. Também está em jogo a espécie e qualidade de vida que a organização e seus participantes levarão e a espécie de participantes que a organização pretende cultivar”. (CHIAVENATO, 1992, p.133)

É sintonizado com estas preocupações que sistematizamos um conjunto de preocupações e práticas da Administração de Recursos Humanos, também desenvolvido por Chiavenato (1992). Tais responsabilidades são apresentadas baseadas nos sub-sistemas desenvolvidos por Chiavenato (1992):

Suprimento ou agregação: preocupa-se com identificação das necessidades de pessoal, pesquisa de mercado de recursos humanos, recrutamento e seleção. Este sub-sistema cuida da proposição e elaboração de critérios e instrumentos para o recrutamento, seleção e adequação das pessoas à dinâmica empresarial.

Aplicação: realiza a análise e descrição de cargos, planejamento e alocação interna de recursos humanos. Este sub-sistema avalia cargos e funções, visando identificar os requisitos que devem possuir seus ocupantes, bem como os níveis compatíveis de remuneração. Elabora também projetos de treinamento e desenvolvimento das pessoas a partir de diagnósticos, procurando recomendar estratégias adequadas para o aumento dos níveis de interesse, satisfação e motivação das pessoas.

Compensação ou manutenção: prioriza salários, benefícios, carreiras, higiene e segurança no trabalho, relações sindicais. Este complexo sub-sistema articulado ao sub-sistema de aplicação lida não só com a remuneração direta, mas indireta, também apóia e estimula o desenvolvimento pessoal e profissional dos trabalhadores e da organização, cuida da higiene e da saúde ocupacional dos trabalhadores e das condições de trabalho, atuando também no processo direto e do assessoramento das negociações com funcionários, clientes e organizações sindicais.

Controle ou monitoração: cuida da avaliação de desempenho, banco de dados, sistemas de informações gerenciais, auditoria em recursos humanos. 
Este sub-sistema acompanha e gerencia as informações da área de Recursos Humanos através da definição de padrões e elaboração de instrumentos para a avaliação das pessoas.

O que ora esboçamos permite visualizar as grandes diretrizes técnicooperacionais da área de Recursos Humanos. De acordo com as características de cada organização, a área prioriza a estrutura e as configurações diferenciadas. É importante destacar que tais sub-sistemas vinculam-se diretamente às políticas de Recursos Humanos, que por sua vez são atreladas à filosofia empresarial. A filosofia da empresa e a política de Recursos Humanos dão o encaminhamento sobre “quem somos e quem queremos ser”, definindo e consolidando, portanto, políticas de identidade que conduzirão à gestão das pessoas na organização.

\section{Desafios contemporâneos: tendências e perspectivas}

Em nossa concepção, independentemente do porte da empresa, do ramo de atividade, da natureza jurídica, a função de Recursos Humanos deve ser enunciada e transparente: seja num órgão ou departamento específico para cuidar de Recursos Humanos, seja numa função subsidiária e/ou sobreposta à outra função ou departamento. Toda organização precisa de profissionais que cuidem da gestão de pessoas. Os profissionais responsáveis pela gestão de Recursos Humanos devem atentar-se também aos aspectos estratégicos que caracterizam a área, evitando o aprisionamento e/ou a supervalorização das atividades que compõem o cotidiano, em detrimento de uma visão estratégica. Isto remete a um duplo aspecto: o profissional de RH deve propor ações que abranjam apenas os sub-sistemas, mas devem estar inseridas no conjunto das estratégias dos negócios.

Num quadro de referencia maior, no qual as organizações estão inseridas, a gestão de pessoas está envolvida, por influência das contínuas e aceleradas mudanças da vida econômica, social, política e empresarial. O profissional de Recursos Humanos deve potencializar suas ações, atentando-se para os desafios que lhe são postos continuamente. Sua agenda profissional deve contemplar: desafios ambientais (globalização, mudanças informacionais e comunicação, diversificação da força de trabalho, participação do estado, ampliação das exigências do mercado, responsabilidade social e ambiental); desafios organizacionais (competitividade, avanços tecnológicos, novos modelos administrativos, cultura organizacional); e os desafios individuais (ética, produtividade, carreira, seguridade, qualidade de vida, etc).

Os propósitos da área, uma vez analisados em seu conjunto, e dialogados continuamente com os responsáveis, sem perder de vista os propósitos maiores da organização.

O ambiente cada vez mais dinâmico das organizações requer profissionais competentes para impulsionar as pessoas e as organizações nos caminhos aparentemente paradoxais da produtividade, do lucro e do resultado, com a satisfação das necessidades humanas, da qualidade de vida e da responsabilidade sócio-ambiental. É certamente, um grande desafio que não que tivemos a ousadia de pretender esgotar no presente artigo, mas que carece de atenção especial de todos e de cada um de nós em nosso cotidiano. Assim, quem sabe, poderemos avançar nos processos éticos e emancipatórios de construção de uma sociedade mais humana e justa, onde o emprego e o trabalho se sobressaem como fatores constitutivos para a ampliação das possibilidades de uma vida digna.

\section{Referências:}

BOOG, G.; BOOG, M. Manual de gestão de pessoas e equipes. São Paulo: ABRH/APARH, E. Gente, 2002.

CHIAVENATO, I. Recursos humanos. Ed. Compacta. 2.ed. São Paulo: Atlas, 1992.

\section{GIL, A.C. Gestão de pessoas. Enfoque nos papéis profissionais. São} Paulo: Atlas, 2001.

TOLEDO, F. de. O que são recursos humanos. 5.ed. São Paulo: Brasiliense, 1986.

TONELI, M.J. Desenvolvimento histórico do RH no Brasil e no mundo. In: BOOG, G.; BOOG, M. Manual de gestão de pessoas e equipes. São Paulo: ABRH/APARH, E. Gente, 2002, p.59-84.

\section{Resumo:}

O presente trabalho propõe refletir sobre o papel da função de Recursos Humanos, a partir de uma breve visão histórica, refletindo a seguir alguns dos seus "saberes e práticas” e subsistemas que norteiam as principais responsabilidades e atividades da área. São apresentados alguns dos desafios contemporâneos que têm sido postos no cotidiano de profissionais que trabalham na gestão de pessoas. Delimitase a função de recursos humanos em seus princípios, estratégias e técnicas vinculadas às organizações produtivas de trabalho. A proposta é disseminar a tese que tem mobilizado nossas ações, enquanto pesquisador e educador: todo profissional é um gestor de pessoas, portanto, deve ter o conhecimento e a sensibilidade para lidar com as pessoas nas situações cotidianas das organizações.

\section{Palavras-chave:}

Gestão de Pessoas; Gestão das Organizações; Administração de Recursos Humanos; Identidade; Multidisciplinariedade. 